\title{
Knowledge Assessment through Surveying on Cattle Zoonotic Diseases in Dairy Farmers
}

\section{Bojiraj Munisamy ${ }^{1}$, Prejit ${ }^{2}$, Praveena Sivanathan ${ }^{3}$ and Porteen Kannan ${ }^{4}$}

${ }^{1}$ Department of Animal Husbandry, Thanthai Roever Institute of Agriculture and Rural Development, Perambalur-621 115, Tamil Nadu, India

${ }^{2}$ Center for One Health Education, Advocacy, Research and Training, Kerala Veterinary and Animal Sciences University, Kerala-673 576, India

${ }^{3}$ Department of Agricultural Business Management and Social Science, Thanthai Roever Institute of Agriculture and Rural Development, Perambalur-621 115, Tamil Nadu, India ${ }^{4}$ Department of Veterinary Public Health and Epidemiology, Madras Veterinary College, Chennai-07, India

*Corresponding author

\section{A B S T R A C T}

The cross sectional study was conducted in 100 dairy farmers at Perambalur district of Tamil Nadu State with a designed questionnaire on different aspects of cattle zoonotic diseases, with the aim of to study the awareness, risk factors of cattle zoonotic diseases, impact in human and animal populations. The study revealed that farmers are belonging between $26-50$ years age $(85 \%)$, male (73\%), both schooling and illiterate farmers $(25 \%)$

\section{Keywords}

KnowledgeAssessment- Cattle Zoonotic diseasesDairy farmers.

\section{Article Info}

Accepted:

15 February 2017

Available Online:

10 March 2017 and annual income (Rs.50, 000-1, 00,000) through dairy farming. 53 per cent farmers had less than 5 dairy cows, 57 per cent dairy farmers had less than 5 years experience. Also study observed that 74 per cent and 77 per cent dairy farmers are aware about deworming and zoonotic diseases respectively. Out of 77 per cent dairy farmers Rabies $(77.3 \%)$, Foot and Mouth Disease (62.0\%) are major known zoonotic diseases. 45, 78 and 64 per cent are aware on usage of disinfection, frequency of disinfection usage in hand washing and frequency of livestock shed cleaning respectively. 44 per cent and 48 per cent spending amount Rs.751-1,000 for treating the disease per year /animal/person respectively. 56 per cent respondents are aware of route of transmission of zoonotic diseases. 33, 30 and 19 per cent received the sources of information from Media, Veterinarian and Physician. 42 per cent dairy farmers showed for signs of cattle zoonotic diseases. Garrett ranking was used to analyze the Specific knowledge about the Zoonotic disease and revealed that knowledge on disease and symptoms of zoonotic diseases is 86.34 per cent. It was concluded that dairy farmers were well aware of rabies and foot and mouth disease but the knowledge toward other zoonotic diseases was low to medium. This study can be used to development of a coordinated, effective one health approach to prevention of zoonotic disease.

\section{Introduction}

Zoonoses as "those diseases and infections which are naturally transmitted between vertebrate animals and man" Zoonotic diseases can be caused by viruses, bacteria, rickettsia, fungi, helminthes, protozoa and arthropods. Approximately 60 percent of all 
described agents of infections of human beings are shared in nature with other vertebrate animals (Daszak et al., 2000). Many animal related problems which negatively affect human health and economy exist in all countries of the world including Zoonoses, food borne diseases and pollution of the environment from animal sources. Most of the agents associated with the current food borne disease out breaks such as Salmonellosis, E. coli, Campylobacteriosis and Listeriosis are of concern especially in the developing countries. In addition, Zoonoses like Rabies, Brucellosis, Bovine Tuberculosis, Cysticercosis, Hydatidosis, Taeniasis and Toxoplasmosis are yet to be considered as uncontrolled diseases which need the attention of veterinary public health services (Babu et al., 2015). Emerging and reemerging zoonotic diseases having a potentially dangerous impact on human health have brought worldwide attention to them. Due to climatic changes, the incidence of emerging and reemerging diseases has increased to a greater extent. In developing countries they constitute an important threat to human health (Woolhouse and Sequeria, 2005). The Indian subcontinent has been identified as one of the four global hot-spots at increased risk for emergence of new infectious diseases (Singh et al., 2011). The zoonotic diseases may be transmitted to livestock farmers through contamination during production, processing, and handling of food products of animal origin. About $68 \%$ of workforce in India is in close contact with domestic animals and their activities, such as working with animals and in their sheds, improper disposal of waste from animal sheds, skinning of infected animals, slaughtering of diseased animals, disposal of infective material from the diseased animals and poor personal hygiene practices, have been reported to be important risk factors (Asokan et al., 2011 and Pavani, 2014). Zoonotic diseases have both direct and indirect effects on livestock health and production. Indirect effects occur as a result of the risk of human disease, the economic impact on livestock producers through barriers to trade, the costs associated with control Programmes, the increased cost of marketing produce to ensure it is safe for human consumption and the loss of markets because of decreased consumer confidence. Lack of awareness about the zoonotic diseases is one of the most important reasons for the outbreak of zoonotic diseases in people. As agriculture and Animal Husbandry are the two important occupations of people in villages, which make them to expose to a number of dangerous zoonotic diseases. Hence, this study was undertaken to study the extent of knowledge, awareness, risks and impact in human and animal populations of zoonotic diseases in dairy farmers.

\section{Materials and Methods}

\section{Sampling area and size}

The cross sectional study was conducted in 100 dairy farmers at Perambalur district of Tamil Nadu state, Dairy farmers, farm labours, farm supervisor, milking man and agricultural cum dairy farmers were selected without adopting any sampling method. Each farmer was interviewed with a preformed questionnaire.

\section{Data collection}

Draft questionnaires were prepared based on the above mentioned criteria as pilot study and those drafts were distributed to three experts for corrections. After the corrections from the experts, a final questionnaire was prepared. The designed questionnaires were distributed to the 100 selected populations (Dairy farmers and Agricultural cum dairy farmers) and collected back after giving a sufficient time period. 


\section{Statistical analysis}

The data were subjected to statistical analysis by percentile analysis and Garrett ranking method.

\section{Results and Discussion}

\section{Demographic distribution details}

Demographic details were collected from 100 dairy farmers and found that 85 per cent were belonging to $26-50$ years age and 73 per cent were male. Only 25 per cent farmers did their schooling. The farmers had an annual income in the range of Rs.50, 000-1, 00,000 through agricultural cum dairy farming. Hundal et al., (2016) also reported that majority of the respondents had age up to 40 years $(70 \%)$ and their qualification of primary to higher secondary level $(77.6 \%$ ). Rajkumar et al., (2016) found in his study that most of the respondents were small-scale farmers and their monthly income was less than Rs. 10,000 (Table 1).

\section{Number of animal, experience and system of rearing}

Out of 100 dairy farmers data analyzed in the study, 53 per cent farmers had less than 5 dairy cows in their farm, 57 per cent dairy farmers are had less than 5 years experience in dairy farming and 59 per cent respondents followed semi intensive method of cattle rearing. Hundal et al., (2016) revealed in his cross sectional study, their herd size up to 10 animals (79.6\%). Tebug (2013) revealed 81 respondents had above six years experience in dairy farming.

\section{Awareness and deworming status on cattle zoonotic diseases}

Present study revealed that 74 per cent and 77 per cent dairy farmers were aware about deworming and zoonotic diseases, respectively. Out of 77 per cent farmer Rabies $(77.3 \%)$, foot and mouth disease $(62.0 \%)$, Tuberculosis (18.1\%), Anthrax (16.8\%) and Brucellosis (11.6 \%) were aware about zoonotic diseases. Chikerema et al., (2013) found that awareness amongst the farmers was known viz., Rabies (88.7\%), Anthrax (71.5\%) and Brucellosis (20.9 \%). Tesfaye et al., (2013) revealed that were rabies $(97.1 \%)$, followed by Taeniasis $(83.4 \%)$, anthrax (55.4 $\%)$, Bovine tuberculosis (29.1\%) and Hydatidosis (4\%) knew on common zoonotic diseases. Also Girma et al., (2012) reported that majorities of respondents were frequently mentioned zoonotic diseases were rabies 384 (100\%) followed by anthrax $362(94.27 \%)$, teniasis 342 (89.06\%), tuberculosis 340 $(88.54 \%)$, brucellosis $190(49.48 \%)$ and 120 $(31.25 \%)$ mentioned other infectious diseases of zoonotic importance.

\section{Hygienic and disinfection awarness on cattle zoonotic diseases}

Among 100 dairy farmers 45, 78 and 64 per cent were aware on usage of disinfection, frequency of disinfection usage in hand washing and frequency of livestock shed cleaning, respectively. Majority of the farmers $(59.3 \%)$ cleaned the shed two times per day with suitable disinfection. A total of 55 per cent and 62 per cent farmers have not used any disinfection and personel protective measures to prevent incidence of zoonotic diseases. Results were correlated with Rajkumar et al., (2016) interviewed with 250 livestock farmers on zoonotic diseases awareness and found that about 61.2 per cent of farmers were keeping their animal shed clean. Overall hygienic practices followed by the farmers during cleaning of udder while milking and during cleaning of sheds were also considered to be negligible Babu et al., (2015). Tebug et al., (2015) reported 70.3 per cent of farmers regularly assist animals during parturition and abortion without protective gloves. A majority of the respondents did not 
use any protection when handling cows having an abortion or when dealing with aborted materials (Lindahl et al., 2015) (Table 2).

\section{Immunosuppressive Person involvement} status in farm activity

Major share of the 22 per cent immunosuppressive farmers involved in dairy farming, also study revealed that 11 respondents had habits of smoking in dairy farm.

\section{Vaccination awareness status against zoonotic diseases}

A total of 19 per cent and 81 per cent farmers were aware about vaccination and its importance and vaccination was done on specific zoonotic disease like FMD respectively. Hundal et al., (2016) revealed that annual vaccination of dogs $(78 \%)$ against rabies and only 47.2 per cent livestock owners were aware of the occurrence of abortion due to brucellosis and availability of prophylactic vaccine $(67.6 \%)$ against it as a preventive measure. Tebug, (2013) significantly higher number of respondents $(75.7 \%)$ had satisfactory level of awareness when compared to those who practiced preventive measures.

Screening status the dairy cattle for zoonotic diseases

29 per cent farmers were screened the dairy cattle for zoonotic diseases. Majority of the dairy farmers were illiterate and never heard about zoonotic diseases that's may be the reason for not screening the dairy cattle for zoonotic diseases.

\section{Expenditure towards treating the diseased animals and sick persons}

44 per cent and 48 per cent were spending Rs.751-1000 for treating the disease per year /animal/person respectively. Study couldn't correlate with other studies due to lack of relevant data and only limited research have been carried out to assess expenditure details for treating the persons and animals.

\section{Awareness about route of transmission of zoonotic diseases}

The present investigation suggests that 56 per cent respondents were aware of route of transmission of zoonotic diseases and also knew ingestion ( $55 \%$ ) was the major route of transmission.

Hundal et al., (2016) opined that 55.6, 67.2, 52.0, 64.0 and 51.2 per cent respondents were aware of the transmission of zoonotic diseases to human being through contaminated milk, meat, air, feed, or through contact with infected animals, respectively. Rajkumar et al., (2016) revealed only 16.4 per cent of respondents knew that diseases in animals can be transmitted to humans through any one of the route. Babu et al., (2015) also found that transmission of zoonotic diseases through consumption of milk $(14.10 \%)$ and meat $(18.58 \%)$.

\section{Involvement of animal husbandry activities}

Involvement of Animal husbandry activities among the sample respondents was categorized into farm labour (68 \%), farm supervisor $(21 \%)$, milking man $(19 \%)$ and others $(11 \%)$ like visitors, agricultural field workers.

Tesfaye et al., (2013) conducted a face to face interview technique with farmers $(n=48)$, smallholder dairy farmers $(n=44)$, butchers $(n=34)$ and city residents $(n=49)$ for assessing the perception of the public on common zoonotic diseases and found that the most frequently known zoonotic diseases among the respondents in the study area were rabies, 
taeniasis, anthrax, bovine tuberculosis and hydatidosis.

Source of getting awareness about the zoonotic diseases

The sources of information on awareness about the zoonotic diseases are 33, 30 and 19 per cent received from media, Veterinarian and Physician respectively.

Tebug, (2013) opined that most of the farmers $(59.3 \%)$ received information about zoonoses through Agricultural extension services.

Table.1 Demographic distribution details

\begin{tabular}{|c|c|c|c|}
\hline Particulars & Classification & No. of respondents & $\%$ \\
\hline \multirow{4}{*}{ Age } & Less than 25 & 06 & 06 \\
\hline & $26-50$ & 85 & 85 \\
\hline & $51-100$ & 09 & 09 \\
\hline & Total & 100 & 100 \\
\hline \multirow{3}{*}{ Sex } & Male & 73 & 73 \\
\hline & Female & 27 & 27 \\
\hline & Total & 100 & 100 \\
\hline \multirow{7}{*}{ Educational status } & Nil & 25 & 25 \\
\hline & Primary & 18 & 18 \\
\hline & SSLC & 25 & 25 \\
\hline & HSC & 16 & 16 \\
\hline & Graduate & 14 & 14 \\
\hline & Post graduate & 02 & 02 \\
\hline & Total & 100 & 100 \\
\hline \multirow{3}{*}{ Occupation } & Dairy farmer & 30 & 30 \\
\hline & Agricultural cum dairy farmer & 70 & 70 \\
\hline & Total & 100 & 100 \\
\hline \multirow{4}{*}{ Socio economic status } & Lower $(<50,000)$ & 37 & 37 \\
\hline & Middle $(50,000-1,00,000)$ & 56 & 56 \\
\hline & Upper $(>10,0000)$ & 07 & 07 \\
\hline & Total & 100 & 100 \\
\hline
\end{tabular}


Table.2 Hygienic and disinfection awareness on zoonotic diseases

\begin{tabular}{|c|c|c|c|c|}
\hline Category & \multicolumn{2}{|c|}{ Awareness status } & No. of respondents & $\%$ \\
\hline \multirow{2}{*}{$\begin{array}{l}\text { No. of usage } \\
\text { disinfection }\end{array}$} & \multicolumn{2}{|c|}{ Yes } & 45 & 45 \\
\hline & \multicolumn{2}{|c|}{ No } & 55 & 55 \\
\hline \multicolumn{3}{|l|}{ Total } & 100 & 100 \\
\hline \multirow{7}{*}{$\begin{array}{l}\text { Personnel protective } \\
\text { measures }\end{array}$} & \multicolumn{2}{|c|}{ Yes } & 38 & 38 \\
\hline & i. & Gloves & 14 & 36.8 \\
\hline & ii. & Face mask & 07 & 18.4 \\
\hline & iii. & Apron & 00 & 00.0 \\
\hline & iv. & Gumboot & 12 & 31.5 \\
\hline & $\mathrm{v}$. & Head cap & 29 & 76.3 \\
\hline & \multicolumn{2}{|c|}{ No } & 62 & 62.0 \\
\hline \multicolumn{3}{|l|}{ Total } & 100 & 100 \\
\hline \multirow{6}{*}{$\begin{array}{l}\text { Frequency of } \\
\text { disinfectant usage for } \\
\text { hand wash }\end{array}$} & \multicolumn{2}{|c|}{ Yes } & 78 & 78.0 \\
\hline & i. & Daily & 45 & 57.6 \\
\hline & ii. & Frequently & 28 & 35.8 \\
\hline & iii. & Weekly & 04 & 05.1 \\
\hline & iv. & Whenever & 01 & 01.2 \\
\hline & \multicolumn{2}{|c|}{ No } & 22 & 22.0 \\
\hline \multicolumn{3}{|l|}{ Total } & 100 & 100 \\
\hline \multirow{6}{*}{$\begin{array}{l}\text { Frequency of livestock } \\
\text { shed cleaning }\end{array}$} & \multicolumn{2}{|c|}{ Yes } & 64 & 64.0 \\
\hline & i. & $<1$ time & 6 & 09.3 \\
\hline & ii. & 2 times & 38 & 59.3 \\
\hline & iii & 3 times & 18 & 28.1 \\
\hline & iv & 4 times & 02 & 3 \\
\hline & \multicolumn{2}{|c|}{ No } & 36 & 36.0 \\
\hline \multicolumn{3}{|l|}{ Total } & 100 & 100 \\
\hline
\end{tabular}



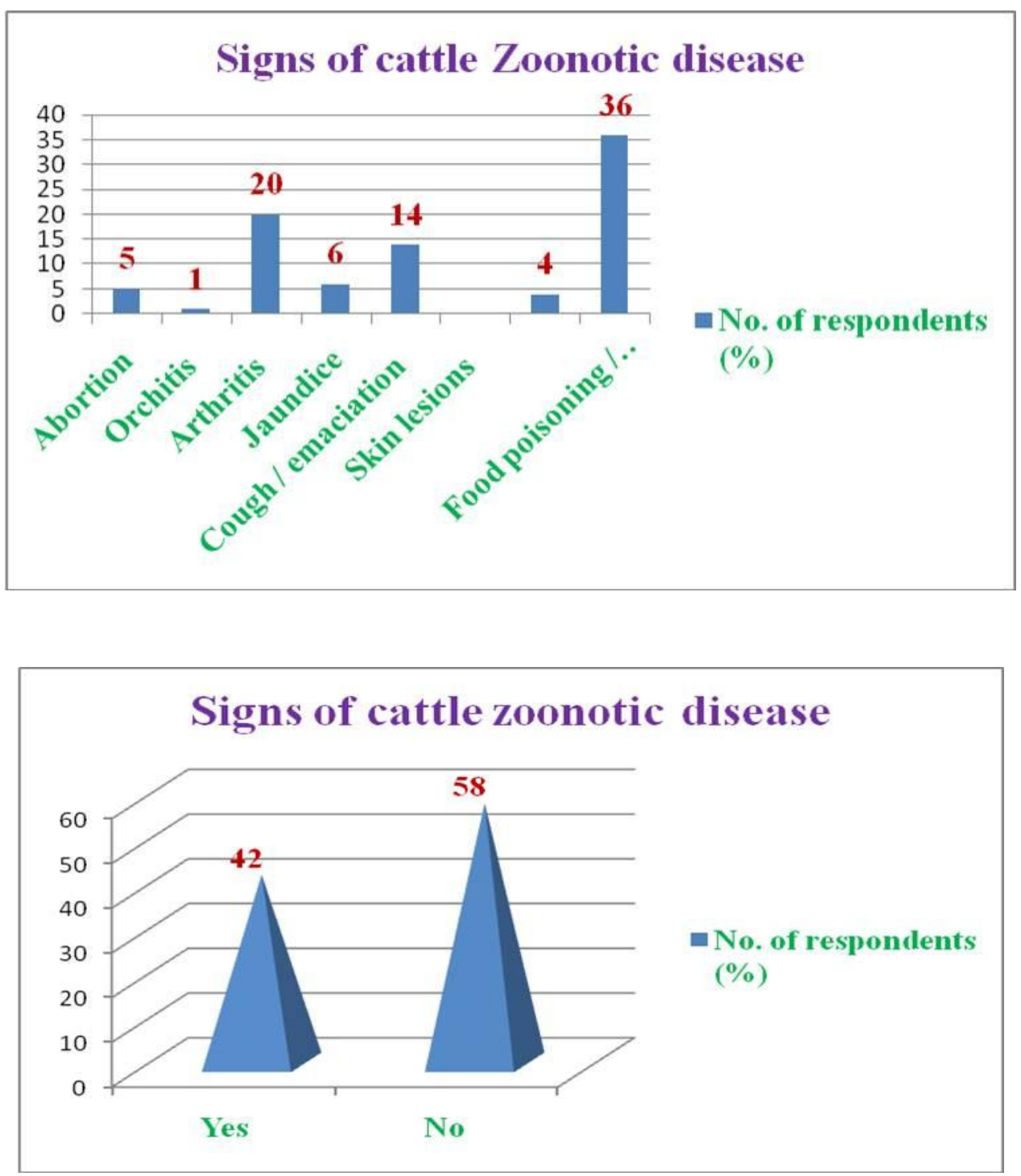

Source of getting awareness about the zoonotic diseases

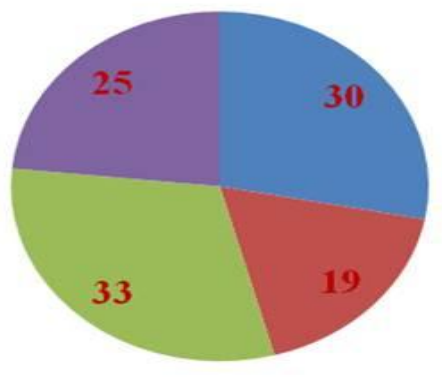

- Veterinarian

- Physician

- Media

- Don't know 

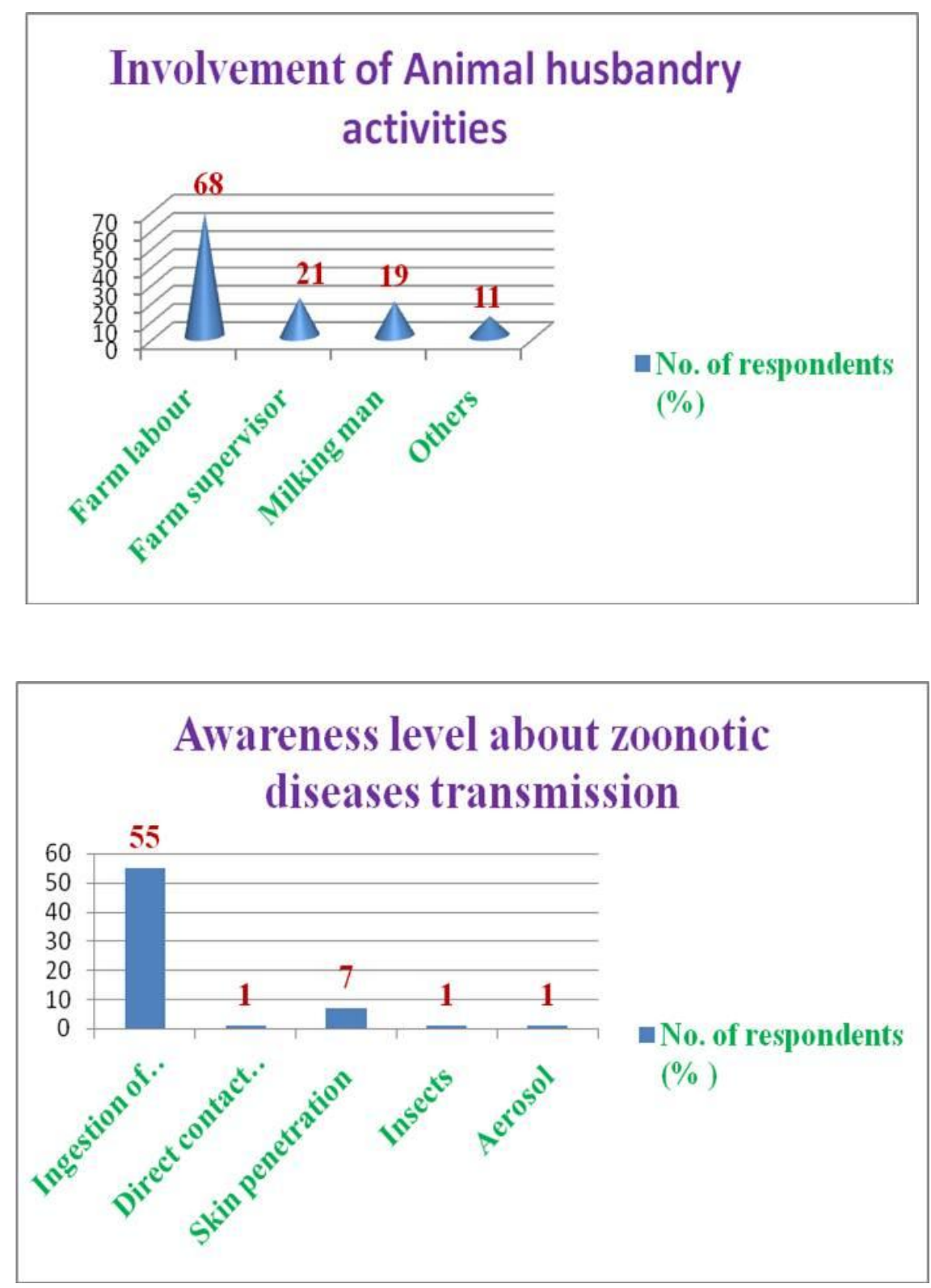

Awareness level about zoonotic diseases transmission
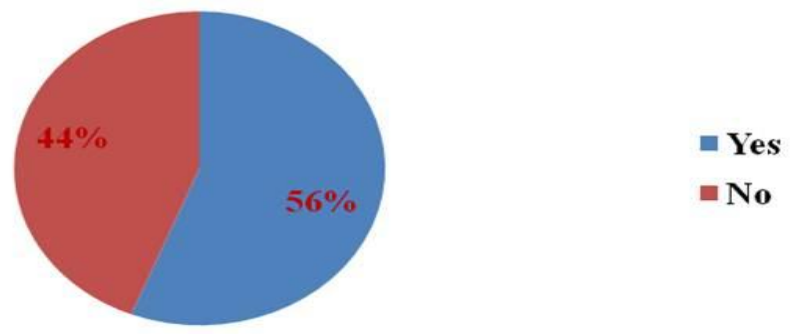

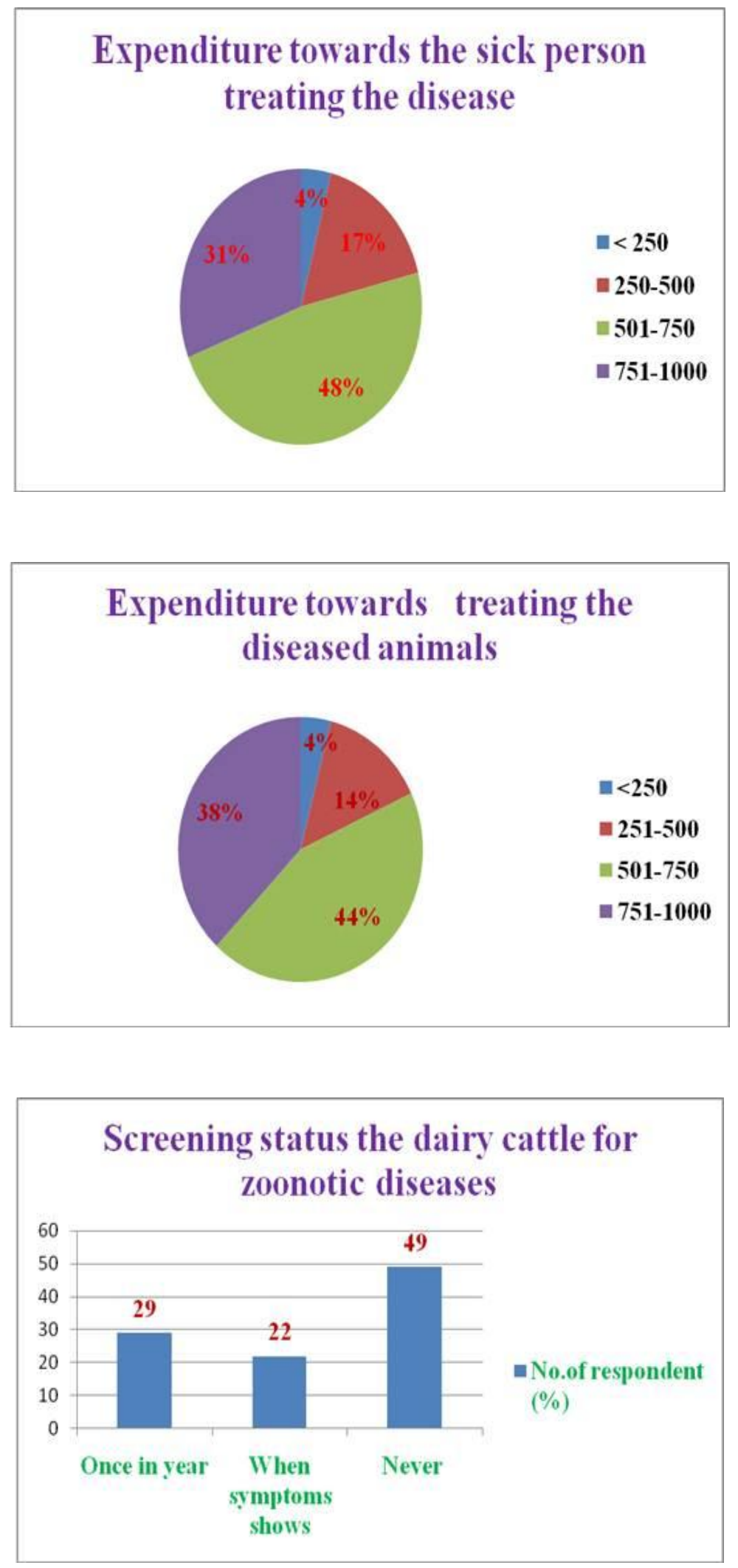

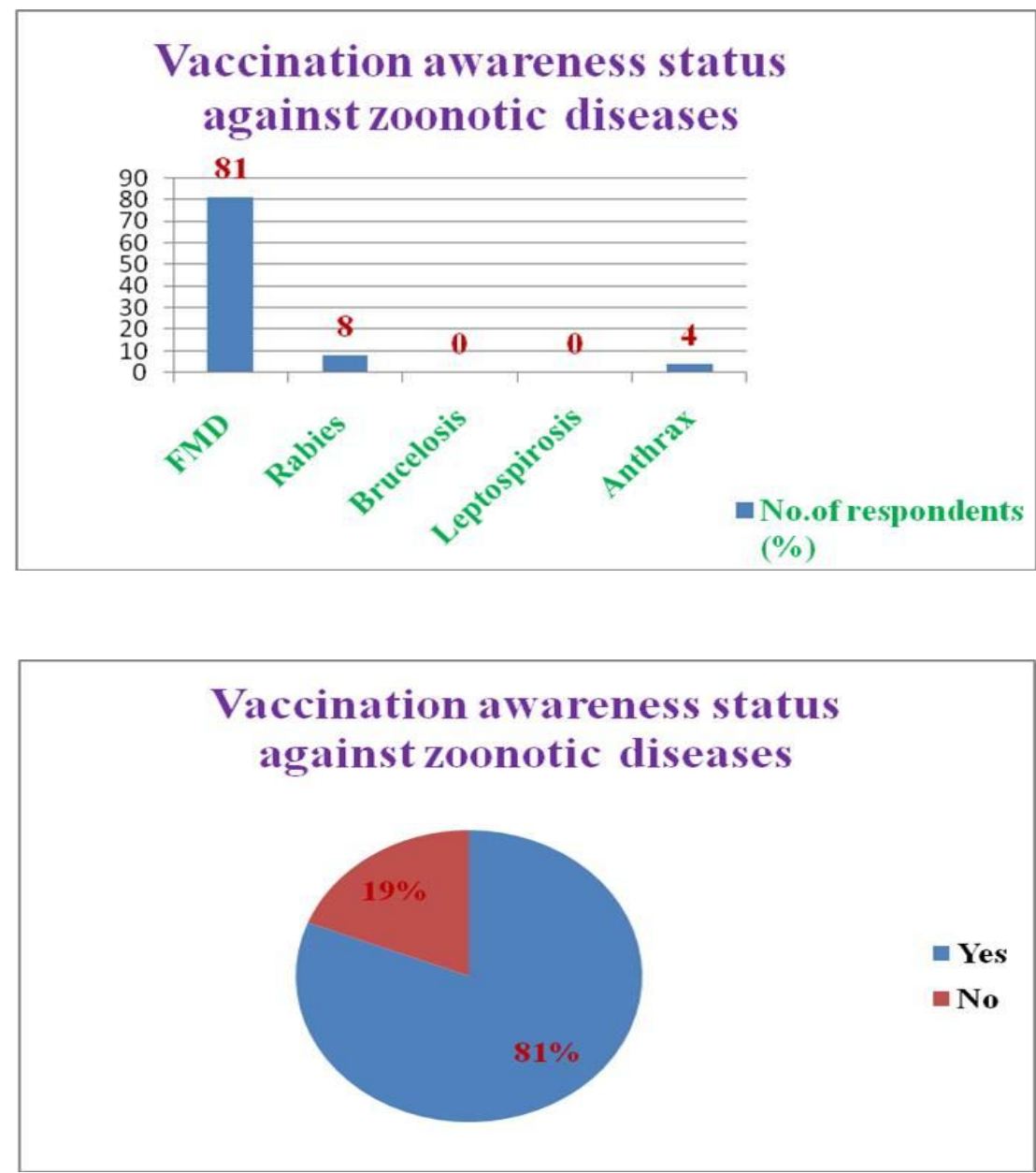

Girma et al., (2012) conducted a qualitative survey in 384 individuals to assess the awareness on food borne zoonosis. $\mathrm{He}$ mentioned that $(85.42 \%)$ of the students got their information from other information sources like their families and 67.71 per cent of health professionals get their information from their medical schools.

\section{History and signs of cattle zoonotic disease}

History signs among the respondents were analyzed among the 100 respondents found that 42 per cent dairy farmers showed for signs of cattle zoonotic diseases. Rajkumar et al., (2016) also reported that in his study 37.7 per cent reported respiratory infection, 31.1 per cent digestive disturbances, 15.5 per cent had dermatological problem and 15.5 per cent reported indiscrete disease such as fever, body pain, and headache joint pain. About 30 per cent of the respondents had an incidence of abortion. Bagaria and Sharma, (2014) revealed that 86 per cent of the total participants perceived a risk of suffering from disease or injury such as Allergies, tuberculosis and bird flu due to animal handling in zoological gardens. In infected persons showed headache $(83.3 \%)$, itching $(80.3 \%)$ and nausea and vomiting $(77.3 \%)$ were the most commonly stated symptoms of diseases transmitted by animals.

Specific knowledge about the zoonotic diseases

Garrett ranking was used to analyze the Specific knowledge about the Zoonotic 
disease. Most of the sample respondents had a knowledge on disease and symptoms of Zoonotic Diseases (86.34\%) followed by mode of transmission routes $(77.12 \%)$, First aid treatment $(65.91 \%)$, and Preventive measures $(58.45 \%)$ and Level of Risks (43.34\%). Similar study was done by Hundal et al., (2016) who observed that 69.2 per cent respondents belonged to low to medium knowledge level categories, whereas 30.8 per cent respondents had high knowledge regarding different aspects of zoonotic diseases in his study.

The study revealed that the livestock farmers were well aware of certain zoonotic diseases like rabies and FMD but the knowledge toward other diseases was low to medium. Even the farmers did not hear the name of few parasites and food borne zoonosis. Education and training to increase the knowledge and skills of different health professionals and for raising awareness by facilitating communication and inter-disciplinary collaboration on research and/or sharing of information between veterinary, public health, agricultural personnel and policy makers. This study can be used to the development of a coordinated, efficient and effective one health approach to the diagnosis, treatment and prevention of zoonotic diseases.

\section{Acknowledgement}

We wish to thank faculty of veterinary and animal sciences, and Center for one health education, advocacy, research and training, Kerala Veterinary and Animal Sciences University, Wayanad-673 576, Kerala, India allowed to do as part of work in Post Graduate Diploma in One Health thesis work. Also we thank Thanthai Roever Institute of Agriculture and Rural Development (Affiliated to Tamil Nadu Agricultural University) Perambalur-621 115, Tamil Nadu, helped for during my study period.

\section{References}

Asokan, G.V., Vanitha, A. and Prathap, T. 2011.One health national programme across species on zoonoses: A call to the developing world. Infect. Ecol. Epidemiol., 1: 8293.

Babu, A.J., Ramya, P., Rao, L.V., Swetha, C.S., Sudhanthiramani and Venkateswara, R. 2015. A study on the awareness and knowledge of zoonotic diseases among the public in and around Proddatur-YSR Kadapa District, Andhra Pradesh, India. Int. J. Rec. Sci. Res., 67: 5131-5138.

Bagaria, A. and Sharma, A.K. 2014. A Knowledge and Practices study of health hazards among animal handlers in zoological gardens. IJOSH, 4(1): 0104.

Chikerema, S.M., Matope, G. and Pfukenyi, D.M. 2013. Awareness and attitude toward zoonoses with particular reference to Anthrax among cattle owners in selected rural communities of Zimbabwe. VBZD, 13(4): 243-249.

Daszak, P., Cunningham, A.A. and Hyatt, A.D.2000. Emerging infectious diseases of wild life threat to biodiversity and human health. Sci., 287: 443.

Girma. S., Zewde, G., Tafess, K. and Jibat, T.2012. Assessment of awareness on food borne zoonosis and its relation with Veterinary Public Health Services in and around Addis Ababa, Ethiopia. Ethiop. Vet. J., 16(1): 15-22.

Hundal, J.S, Sodhi, S.S., Gupta, A., Singh, J. and Chahal, U.S. 2016. Awareness, knowledge, and risks of zoonotic diseases among livestock farmers in Punjab. Vet. World, 9(2): 186-191.

Lindahl, E., Sattorov, N., Boqvist, S. and Magnusson, U. 2015. A Study of Knowledge, Attitudes and Practices Relating to Brucellosis among SmallScale Dairy Farmers in an Urban and 
Peri-Urban Area of Tajikistan. PLoS ONE, 10(2): 1-10.

Pavani, G. 2014. Zoonotic diseases with special reference to India. JMS, 4(1): 73-87.

Rajkumar, K., Bhattacharya, A., David, S., Balaji, S.H., Hariharan, R., Jayakumar, M. and Balaji, N. 2016. Sociodemographic study on extent of knowledge, awareness, attitude, and risks of zoonotic diseases among livestock owners in Puducherry region, Vet. World, 9(9): 1018-1024.

Singh, B.B., Sharma, R., Gill, J.P.S., Aulakh, R.S. and Banga, H.S. 2011. Climate change, zoonoses and India. Rev. Sci. Tech. Off. Int. Epiz., 30: 779-788.

Tebug, S.F., Kamga-Waladjo, A.R., Ema, P. J., Muyeneza, C., Kane, O., Seck, A.,
Ly, M.T. and Lo, M. 2015. Cattle farmer awareness and behavior regarding prevention of zoonotic disease transmission in Senegal. $J$. Agromed., 20(2): 217-24.

Tebug, S.F. 2013. Factors associated with milk producer's awareness and practices in relation to zoonoses in northern Malawi. Vet. World, 6(5): 249-253.

Tesfaye, D., Fekede, D., Tigre, W., Regassa, A. and Fekadu, A. 2013. Perception of the public on the common zoonotic diseases in Jimma, Southwestern Ethiopia. Int. J. Med. Med. Sci., 5(6): 279-285.

Woolhouse, M.E.J. and Sequeria, S. 2005. Host range and emerging and reemerging pathogens. Emerg. Infect. Dis., 11: 1842-1847.

\section{How to cite this article:}

Bojiraj Munisamy, Prejit, Praveena Sivanathan and Porteen Kannan. 2017. Knowledge Assessment through Surveying on Cattle Zoonotic Diseases in Dairy Farmers. Int.J.Curr.Microbiol.App.Sci. 6(3): 783-794. doi: https://doi.org/10.20546/ijcmas.2017.603.091 